\title{
A novel species of Heterophoxus Shoemaker, 1925 (Crustacea, Amphipoda, Phoxocephalidae) from southeast and southern Brazil, with an identification key to world species of the genus
}

\author{
Luiz F. ANDRADE ${ }^{1, *} \&$ André R. SENNA ${ }^{2}$ \\ ${ }^{1}$ Universidade Federal Rural do Rio de Janeiro, Programa de Pós-graduação em Biologia Animal, \\ Decanato de Pesquisa e Pós-Graduação, UFRRJ, Rod. BR 465, Km 7, \\ Seropédica, RJ, CEP 23890-000, Brazil. \\ ${ }^{2}$ Universidade do Estado do Rio de Janeiro, Faculdade de Formação de Professores, \\ Departamento de Ciências, Rua Dr. Francisco Portela, 1470, Patronato, São Gonçalo, \\ RJ, CEP 24435-005, Brazil. \\ *Corresponding author: 1zflp.andrade@hotmail.com \\ 2Email: senna.carcinologia@gmail.com \\ ${ }^{1}$ urn:1sid:zoobank.org:author:FC1B5DFE-8499-425A-8A42-760F71AF6315 \\ ${ }^{2}$ urn:lsid:zoobank.org:author:01438506-4EE8-4F31-B202-F426005866C8
}

\begin{abstract}
This paper describes a novel species of the genus Heterophoxus Shoemaker, 1925 from Brazil. The material examined was collected during the Mini Biological Trawl Project, off southeast and southern Brazil's coast off the states of Rio de Janeiro, Santa Catarina, and Rio Grande do Sul, ranging in depth from 25 to 128 meters. The new species, H. shoemakeri sp. nov., is similar to H. videns K.H. Barnard, 1930; however, the former species can be distinguished by: pereopod 7 basis posterior margin serrate with acute teeth, merus posterior margin not produced; epimeral plate 3 posteroventral corner with a longer acute projection, posterior margin almost straight; uropod 3 outer ramus article 2 clearly notable in both sexes. For Brazilian waters, this is the second record of the genus and the first species described with type material from the country. Besides that, we provide an identification key for the world species of Heterophoxus and a distribution map for the new species.
\end{abstract}

Keywords. Amphipods, taxonomy, Harpiniinae, southwestern Atlantic, Peracarida, new species.

Andrade L.F. \& Senna A.R. 2020. A novel species of Heterophoxus Shoemaker, 1925 (Crustacea, Amphipoda, Phoxocephalidae) from southeast and southern Brazil, with an identification key to world species of the genus. European Journal of Taxonomy 592: 1-16. https://doi.org/10.5852/ejt.2020.592

\section{Introduction}

The genus Heterophoxus Shoemaker, 1925 was erected with the type species H. pennatus Shoemaker, 1925 and shortly after, the species $H$. videns K.H. Barnard, 1930 and H. trichosus K.H. Barnard, 1932 were described based on material from Antarctica. In further work on the revision of the family Phoxocephalidae Sars, 1891, J.L. Barnard (1958) assigned the species Harpinia oculata Holmes, 1908 
and Ha. ophthalmica Schellenberg, 1925 to Heterophoxus based on the following examined characters: presence of eyes, antenna 2 with an ensiform process on the first article and short maxilliped palp, bearing a long seta. In the same research work, the author synonymized H. oculatus (Holmes, 1908) with $H$. pennatus, the type species of the genus.

Jarret \& Bousfield (1994) described H. ellisi Jarret \& Bousfield, 1994 from the northern Pacific and invalidated J.L. Barnard's synonymy, stating that the character analysis by the author was not enough to support his decision. Therefore, the species $H$. oculatus and $H$. pennatus should be kept as valid. Griffiths (1975) described H. cephalodens Griffiths, 1975 and H. opus Griffiths, 1975 with material from South Africa. Ren (1991) described H. pellusidus Ren in Ren \& Huang, 1991 from the Antarctic region and Alonso (2012) described $H$. despard Alonso, 2012 from the Beagle Channel in Argentina.

So far, the only Heterophoxus species reported from Brazilian waters was $H$. videns, recorded from the state of São Paulo (Wakabara et al. 1991; Valério-Berardo 1992; Wakabara \& Serejo 1998; ValérioBerardo et al. 2000; Rodrigues \& Pires-Vanin 2012; Serejo \& Siqueira 2018); however, none of these works present illustrations of the sampled specimens. The Brazilian record of $H$. videns is considered extralimital (Alonso de Pina et al. 2008), since the previous records of the species are from areas with very different water temperature conditions such as the Antarctic shelf and the Magellanic region. This work presents the first species of Heterophoxus described with type material from Brazil.

\title{
Material and methods
}

The material examined was collected by the R/V Prof. Wladimir Besnard, off Brazil's southeastern coast off the states of Rio de Janeiro, Santa Catarina and Rio Grande do Sul in 1970 and 1971, with rectangular dredges at depths ranging from 25 to 128 meters. The campaign was organized by the Instituto Oceanográfico, Universidade de São Paulo, in the scope of the Mini Biological Trawl (MBT) Project. All specimens are preserved in 70\% ethanol and deposited at the Crustacea Collection of the Universidade do Estado do Rio de Janeiro (UERJ). For the taxonomic study, the mouthparts and appendages were dissected and mounted in glycerin gel slides. The drawings were made under an optical microscope with camera lucida, Motic BA-310, and digitalized with CorelDRAW 2018. The distribution map was built with the software QGIS 3.2.1. The setal classification adopted in this paper follows Garm \& Watling (2013) and the nomenclature of gnathopod palms is based on Poore \& Lowry (1997).

\section{Results}

Taxonomy

\author{
Order Amphipoda Latreille, 1816 \\ Suborder Amphilochidea Boeck, 1871 \\ Family Phoxocephalidae Sars, 1891 \\ Subfamily Harpiniinae Barnard \& Drummond, 1978
}

Genus Heterophoxus Shoemaker, 1925

\section{Type species}

Heterophoxus pennatus Shoemaker, 1925

Diagnosis (modified from Barnard \& Karaman 1991)

Rostrum unconstricted. Eyes present. Antenna 1, article 2 short, ventral setae widely spread, but almost confined apically. Antenna 2, article 1 strongly ensiform, facial stout setae on article 4 in one main row, article 5 very short. Mandible, right incisor with 4+ teeth, right lacinia mobilis bifid, flabellate, molar not triturative, with three basally fused stout setae; palpar hump medium, apex of palp article 3 
oblique. Maxilla 1, inner plate, with two setae, palp 2-articulate. Maxilliped, inner plate, partly fused, poorly armed, apex of palp article 3 not strongly protuberant, article 4 not elongate, but apical nail distinct. Gnathopods small, similar, carpus of gnathopods 1-2 very short, without eusirid attachment, almost cryptic, propodus of gnathopods 1-2 ovatorectangular, elongate, poorly setose anteriorly, palms acute. Perepods 3-4, carpus with posteroproximal setae, propodus with thin armaments. Pereopod 5, basis, merus and carpus narrow. Pereopod 6, merus and carpus narrow. Pereopod 7 of ordinary size, ischium enlarged, dactylus ordinary. Epimeral plates 1-2 without long midfacial brushes or posterior setae. Epimeral plate 3 ordinary, bearing three or more long setae. Urosomite 3 without dorsal hook. Uropod 1, peduncle without inter-ramal spike, without displaced stout setae. Uropod 2, inner ramus ordinary. Uropod 3 ordinary, one of rami longer than peduncle, bearing article 2 on outer ramus, with two apical setae. Telson ordinary or with supernumerary lateral stout setae.

\section{Composition}

The genus is composed of 10 known species +1 new species: Heterophoxus cephalodens Griffiths, 1975; H. despard Alonso, 2012; H. ellisi Jarret \& Bousfield, 1994; H. oculatus (Holmes, 1908); H. ophthalmicus (Schellenberg, 1925); H. opus Griffiths, 1975; H. pellusidus Ren in Ren \& Huang, 1991; H. pennatus Shoemaker, 1925; H. shoemakeri sp. nov.; H. trichosus K.H. Barnard, 1932 and H. videns K.H. Barnard, 1930.

\section{Heterophoxus shoemakeri sp. nov. urn:1sid:zoobank.org:act:B3D28885-EAEE-49E9-974C-528AB9B28BE7}

Figs 1-6

\section{Diagnosis}

Head, eyes present, rostrum unconstricted. Antenna 2, peduncle article 1 ensiform; article 4 without posteroproximal lobe, with one brush seta facially. Mandible, molar as a small hump with three stout setae, right lacinia mobilis bifid, left lacinia mobilis flabellate. Maxilla 1, inner plate with two plumose setae; palp 2-articulate. Maxilliped, inner plate with one stout seta apically; palp, article 4 with long apical nail. Gnathopods 1-2, carpus subtriangular; propodus, palm acute and subchelate. Pereopod 5, coxa strongly expanded posteroventrally; basis narrow and slender. Pereopod 6 as long as than the other pereopods. Pereopod 7, basis expanded posteroventrally, exceeding half of merus. Epimeral plate 3, posteroventral corner with an acute projection, posterior margin covered with setules. Uropods 1-2, rami with stout setae, but not distributed continuously to apex. Uropod 3, outer ramus about twice as long as inner ramus, article 2 short, with two long setae apically; inner ramus with one long seta apically. Telson short, about $65 \%$ cleft, each lobe with 1 stout seta apically.

\section{Etymology}

The species name is a tribute to Dr Clarence Raymond Shoemaker, for his worldwide contributions to the knowledge of the amphipods.

\section{Material examined}

Holotype

BRAZIL • +; coast of Rio de Janeiro State, MBT station 141; $23^{\circ} 25^{\prime} \mathrm{S}, 43^{\circ} 00^{\prime} \mathrm{W}$; depth $113 \mathrm{~m} ; 2$ Sep. 1970; dredged; UERJ 433.

\section{Paratypes}

BRAZIL $-1 \mathrm{O}^{\prime}$; coast of Rio de Janeiro State, MBT station 206; $23^{\circ} 14^{\prime} \mathrm{S}, 44^{\circ} 03^{\prime} \mathrm{W}$; depth $52 \mathrm{~m}$; 3 Jun. 1971; dredged; UERJ 434 • 1 subadult ${ }^{\top}$; same collection data as for holotype; UERJ 435 • 14 우우

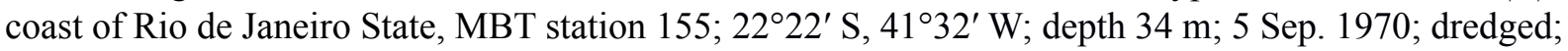


UERJ 436 - 1 ; ; coast of Rio de Janeiro State, MBT station 210; $23^{\circ} 46^{\prime} \mathrm{S}, 43^{\circ} 10^{\prime} \mathrm{W}$; depth $128 \mathrm{~m}$; 4 Jun. 1971; dredged; UERJ $437 \cdot 2$ + 9 ; coast of Santa Catarina State, MBT station 129; $29^{\circ} 13^{\prime}$ S,

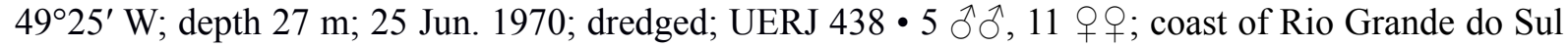
State, MBT station 137; 3003' S, 50 $04^{\prime} \mathrm{W}$; depth 25 m; 26 Jun. 1970; dredged; UERJ $439 \bullet 9$ 우; coast of Rio Grande do Sul State, MBT station 127; 29 $33^{\prime}$ S, 48 $46^{\circ}$ W; depth 118 m; 25 Jun. 1970; dredged; UERJ 440.

\section{Description}

\section{Holotype}

Habitus. As in Fig. 1A.

HeAD (Fig. 2A). Eyes present, rounded, dark in alcohol; rostrum entire, unconstricted. Antenna 1 (Fig. 2B), peduncle article 1 stout, about $1.4 \times$ as long as wide, ventral margin with four brush setae, dorsal margin with setules and one pappose seta distally; article 2, short, ventral margin with seven long pappose setae, facial margin with one brush seta; article 3, short, ventral margin with two setae, facial margin with two brush setae and three simple setae distally; primary flagellum 7-articulate; accessory flagellum 5-articulate. Antenna 2 (Fig. 2C), peduncle article 1 ensiform; article 3, ventral margin with three pappose setae, dorsal margin with one long seta distally; article 4, ventral margin with long pappose setae, facial margin with two brush setae and a row of long setae extending to dorsal apex; article 5, about $0.7 \times$ the length of article 4 , ventral margin with five pappose, one brush seta and two distal setae; flagellum 7-articulate. Left mandible (Fig. 2D), molar as a small hump with three bipectinate stout setae, incisor with five teeth, lacinia mobilis flabellate, accessory setal row with 10 multicuspidate stout setae, palpar hump medium; palp 3-articulate, article 1 short, article 2, curved, about $4.6 \times$ as long as wide, with one medial and two distal setae, article 3 , about $1.2 \times$ as long as article 2 , with two long setae medially, apex oblique, with six medium to long setae. Right mandible (Fig. 2E), molar as a small hump with three bipectinate stout setae, incisor with seven teeth, lacinia mobilis bifid, with small cusps, accessory setal row with eight multicuspidate stout setae, palpar hump medium; palp 3-articulate, article 1 short, article 2, curved, about $4.7 \times$ as long as wide, with one proximal and three distal setae, article 3, about $1.4 \times$ as long as article 2 , with two long setae medially, apex oblique, with seven medium to long setae. Maxilla 1 (Fig. 2G), inner plate with two plumose setae; outer plate, with nine stout multicuspidate setae; palp 2-articulate, article 2 with six setae forming a row medially and two stout plus two long setae apically. Maxilla 2 (Fig. 2H), inner plate subequal to outer plate, with nine plumose setae, medial margin with row of setules; outer plate, with eight long pectinate setae apically and two mid-lateral setae, lateral margin with row of setules. Maxilliped (Fig. 2F), inner plate with one short stout seta apically and six long plumose setae; outer plate with seven stout setae medially, two stout paposerrate setae apically and two long pappose setae laterally, with the exception of the proximalmost ones, these setae are strongly curved; palp, article 2, medial margin weakly setose, article 3 subrounded, weakly setose, article 4 subtriangular, with two setae on the sides, two apical setae and one long apical nail.

Pereon. Gnathopod 1 (Fig. 3A), coxa, ventral margin expanded, convex, with 15 pappose setae; basis, about $2.4 \times$ as long as wide, posterior margin with four long plumose setae medially and three long setae distally; ischium small and subrectangular, posterior margin with one pappose and two simple setae; merus, posterior margin with five pappose setae, facial margin with one long seta; carpus short, $1.2 \times$ as long as wide, anterior margin with one seta distally, posterior margin with seven long setae; propodus, $2.2 \times$ as long as wide, anterior margin with a tuft of setae distally, posterior margin weakly setose, with one stout seta defining palm, palmar hump large; palm acute; dactylus reaching palmar corner, outer margin with one short seta distally. Gnathopod 2 (Fig. 3B) slightly larger than gnathopod 1; coxa subrectangular, ventral margin with nine pappose setae, anterior margin very weakly concave; basis about $2.9 \times$ as long as wide, posterior margin with two long setae medially and three long pappose setae distally; ischium small and subrectangular, posterior margin with two long pappose setae and row of 
four pappose setae extending to facial margin; merus, posterior margin with six pappose setae, facial margin with one pappose seta; carpus short, subtriangular, slightly wider than long, anterior margin with one long seta distally, posterior margin with two pappose and two simple setae; propodus, $2 \times$ as long as wide, anterior margin with tuft of setae distally, posterior margin weakly setose, with one stout seta defining palm, palmar hump large; palm acute; dactylus reaching palmar corner, outer margin with one short seta distally. Pereopod 3 (Fig. 3C), coxa subrectangular, ventral margin with eight plumose setae; basis about $2.6 \times$ as long as wide, posterior margin with four long setae medially and four long pappose setae distally; ischium small and subrectangular, posterior margin with row of six pappose setae extending to facial margin; merus expanded anteriorly, anterior margin with five pappose setae distally, posterior margin moderately setose with medium to long pappose setae; carpus, posterior margin moderately setose, with two stout setae, being the distalmost almost reaching apex of dactylus; propodus, posterior margin with six long setae; dactylus, about $50 \%$ the length of propodus. Pereopod 4 (Fig. 3D), coxa strongly expanded posteriorly, posterodorsal margin excavate, ventral margin with
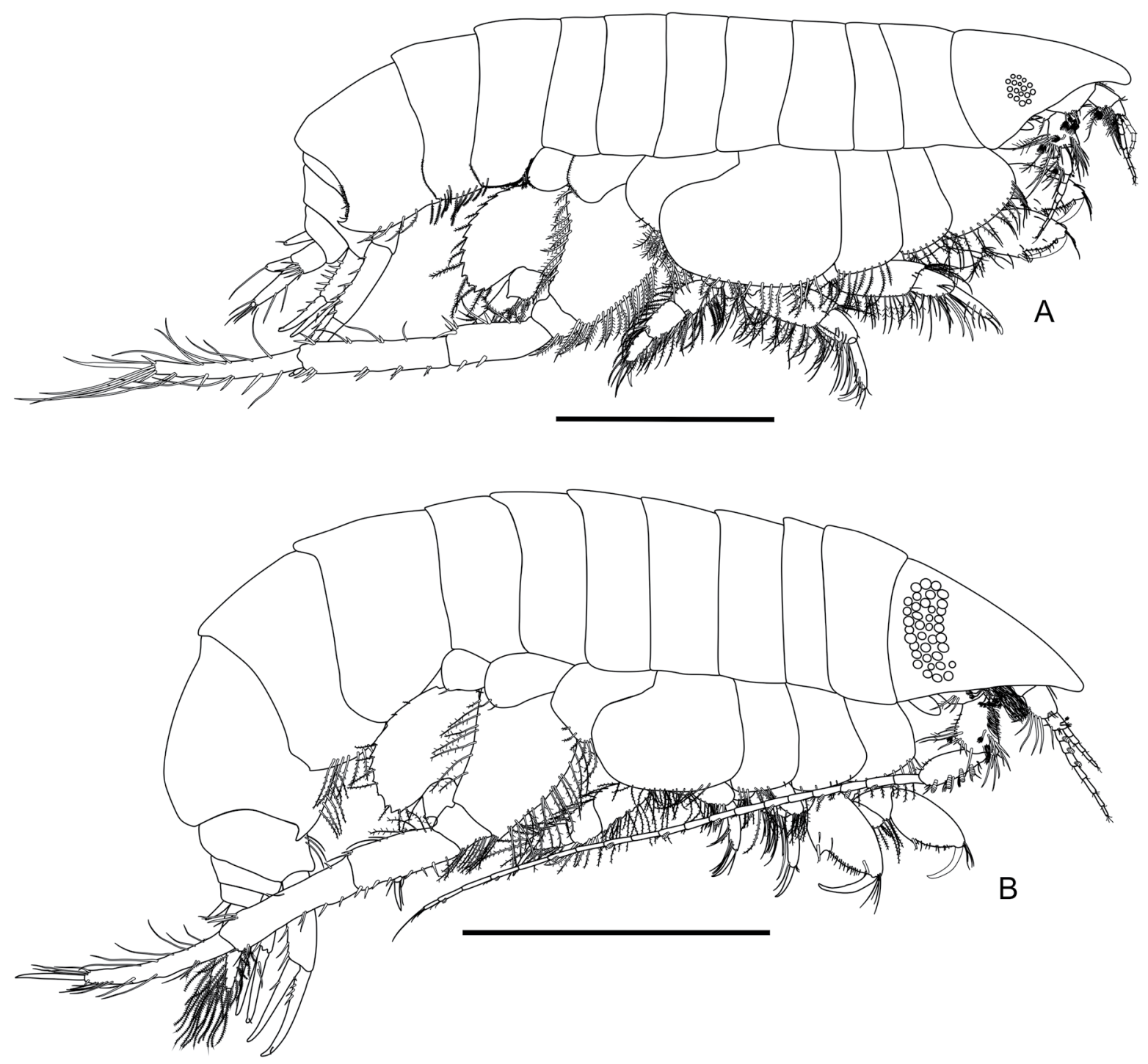

Fig. 1. Heterophoxus shoemakeri sp. nov., habitus. A. Holotype, $q$ (UERJ 433). B. Paratype, $\overbrace{}^{\Uparrow}$ (UERJ 434). Scale bars $=1.0 \mathrm{~mm}$. 

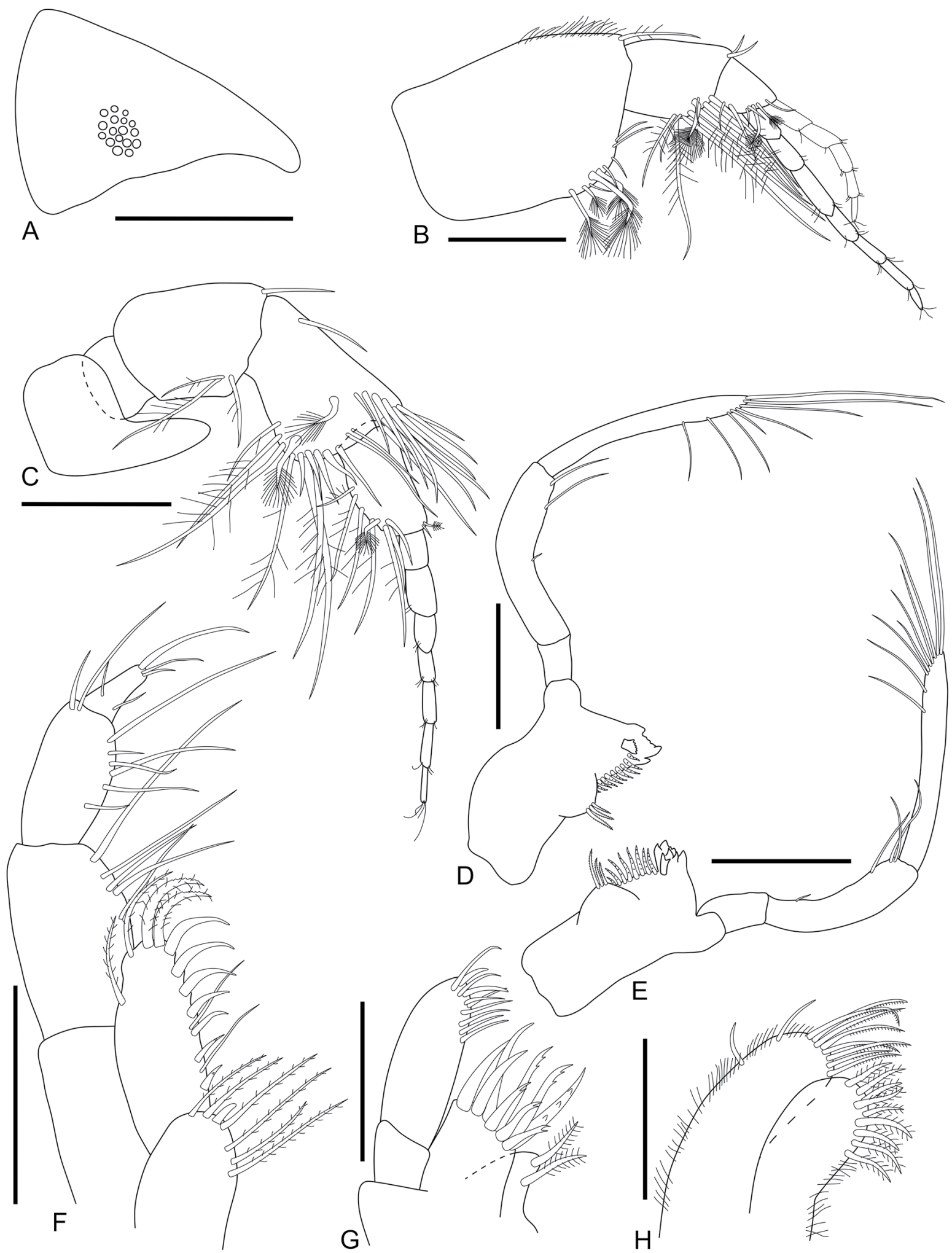

Fig. 2. Heterophoxus shoemakeri sp. nov., holotype,, (UERJ 433). A. Head. B. Antenna 1. C. Antenna 2. D. Left mandible. E. Right mandible. F. Maxilliped. G. Maxilla 1. H. Maxilla 2. Scale bars: A=0.5 mm; $\mathrm{B}-\mathrm{F}=0.2 \mathrm{~mm} ; \mathrm{G}-\mathrm{H}=0.1 \mathrm{~mm}$. 


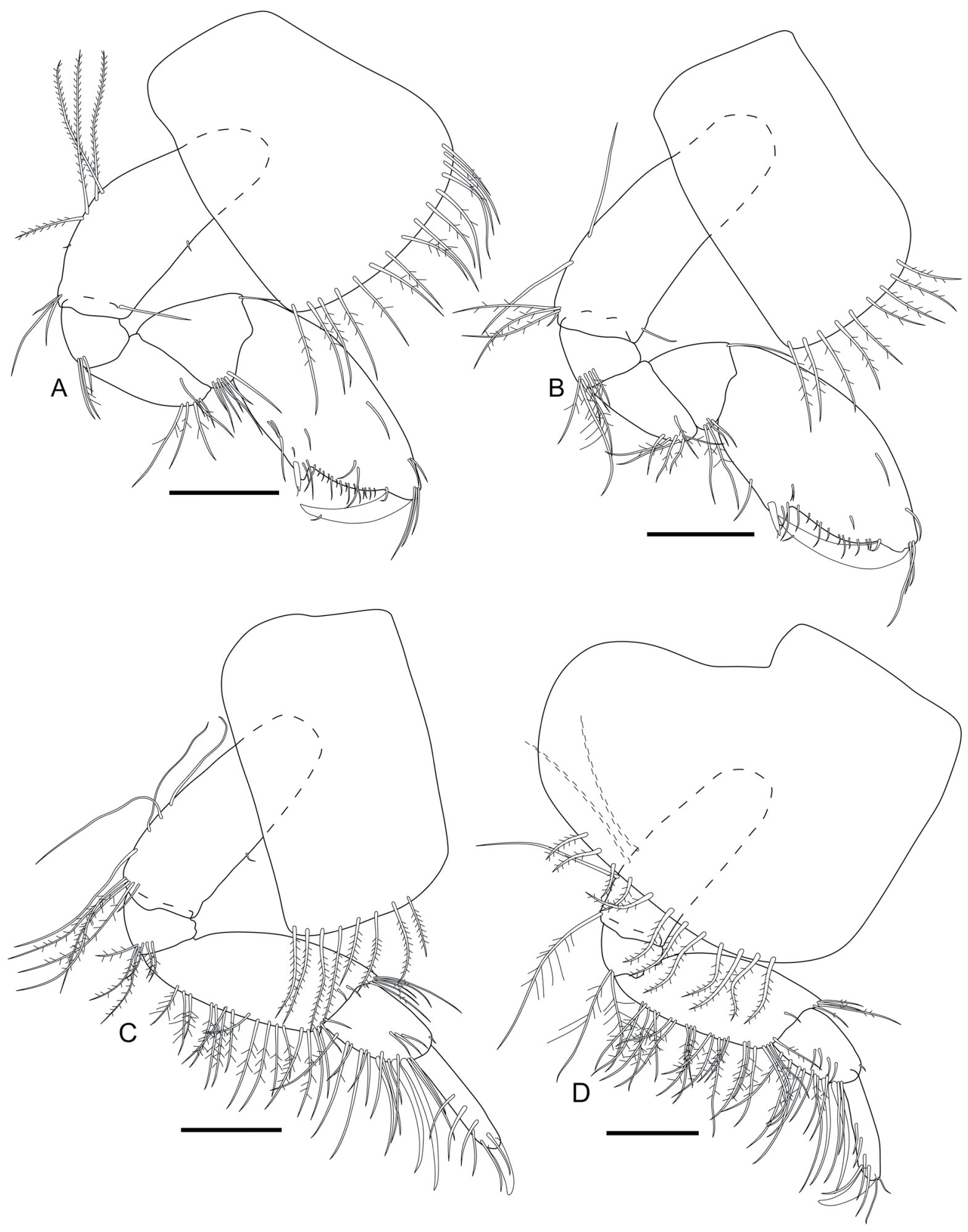

Fig. 3. Heterophoxus shoemakeri sp. nov., holotype, + (UERJ 433). A. Gnathopod 1. B. Gnathopod 2. C. Pereopod 3. D. Pereopod 4. Scale bars $=0.2 \mathrm{~mm}$. 
12 plumose setae; basis, about $2.7 \times$ as long as wide, posterior margin with three long setae medially, posterodistal corner with one long pappose seta; ischium, small and subrectangular, posterodistal corner with two long pappose setae; merus, anteriorly expanded, posterior margin moderately setose with long pappose setae; carpus, anterior margin with one short seta distally, posterior margin moderately setose, facial margin with four setae, with two stout setae, being the distalmost almost reaching the apex of dactylus; propodus, anterior margin with two short setae distally, posterior margin with five long setae; dactylus, about $55 \%$ as long as propodus. Pereopod 5 (Fig. 4A), coxa bilobate, expanded posteroventrally, posteroventral lobe with six pappose setae; basis, about $2.9 \times$ as long as wide, anterior margin with two long setae medially and three pappose and one simple seta distally, posterior margin with one long pappose seta medially; ischium small and subrectangular, anterior margin with three pappose setae distally; merus, anterior margin moderately setose, with three stout setae medially and a row of four stout setae extending to facial margin, posterior margin with four long pappose setae medially and one plumose and one stout seta distally; carpus, anterior margin moderately setose, with long pappose and stout setae, posterior margin with five plumose and two stout setae medially, distally with three plumose and three stout setae; propodus, anterior margin with one stout and three pappose setae, posterior margin with one stout and four plumose setae medially, facial margin five long and two stout setae distally; dactylus, about $70 \%$ as long as propodus. Pereopod 6 (Fig. 4B), much longer than the remaining pereopods; coxa, weakly expanded posteroventrally, posterior margin with one short seta and covered with setules; basis, about $1.3 \times$ as long as wide, anterior margin convex, posterior margin concave, margins covered with plumose setae; ischium, small and subrectangular, anterior margin with two plumose setae; merus, $2.7 \times$ as long as wide, anterior margin with two stout setae, posterior margin with two plumose setae proximally, one stout and one long seta medially, and three stout setae distally; carpus, anterior margin with four sets of stout setae (2-2-2-3), posterior margin with three long and four stout setae; propodus, $8.6 \times$ as long as wide, anterior and posterior margins with long and stout setae; dactylus elongate, about $60 \%$ the length of propodus. Pereopod 7 (Fig. 4C), coxa, small and subrounded, posteroventral margin with one short seta and row of setules; basis, about $1.3 \times$ as long as wide, strongly expanded posteroventrally, exceeding half of merus, posterior margin serrate, with plumose setae in inter-dental notches; ischium, $1.5 \times$ as long as wide, distal lobe produced, anterior margin with two stout setae medially, anterodistal corner with three pappose setae; merus, anterior margin with four stout and three pappose setae, posterior margin with two stout setae distally; carpus, anterior margin with three setae, posterior margin with two plumose setae distally; propodus, anterior and posterior margins with two setae each; dactylus, elongate, slightly longer than propodus.

Pleon. Epimeral plate 1 (Fig. 5A), anteroventral corner with two plumose setae, posterior margin convex, anteromedial to posterior margins covered with setules. Epimeral plate 2 (Fig. 5B), anteroventral corner rounded, ventral margin with six plumose setae, posteroventral corner with a small subrounded projection, posterior margin convex, covered with setules. Epimeral plate 3 (Fig. 5C), anteroventral corner rounded, ventral margin weakly concave, with four plumose and four pappose setae, posteroventral corner with a long acute projection, posterior margin covered with setules. Uropod 1 (Fig. 5D), peduncle $4.8 \times$ as long as wide, dorsomedial margin with five stout setae, dorsolateral margin with two stout setae; outer ramus, dorsal margin with two stout setae and one apical nail; inner ramus subequal to outer, dorsal margin with two stout setae. Uropod 2 (Fig. 5E), peduncle $2.8 \times$ as long as wide, dorsomedial margin with six stout setae, ventrolateral margin with two stout setae; outer ramus, dorsal margin with two stout setae and one subapical seta; inner ramus subequal to outer, dorsolateral margin with one stout seta. Uropod 3 (Fig. 5F), peduncle $1.8 \times$ as long as wide, with five stout setae distally; outer ramus, article 1, lateral margin with two long setae, apical margin with one short and two long setae, article 2 , short, about $1.7 \times$ as long as wide, with two long setae apically; inner ramus, about $50 \%$ the length of outer, with one long seta apically. Telson (Fig. 5G), short, about $65 \%$ cleft, with one stout seta on each lobe. 


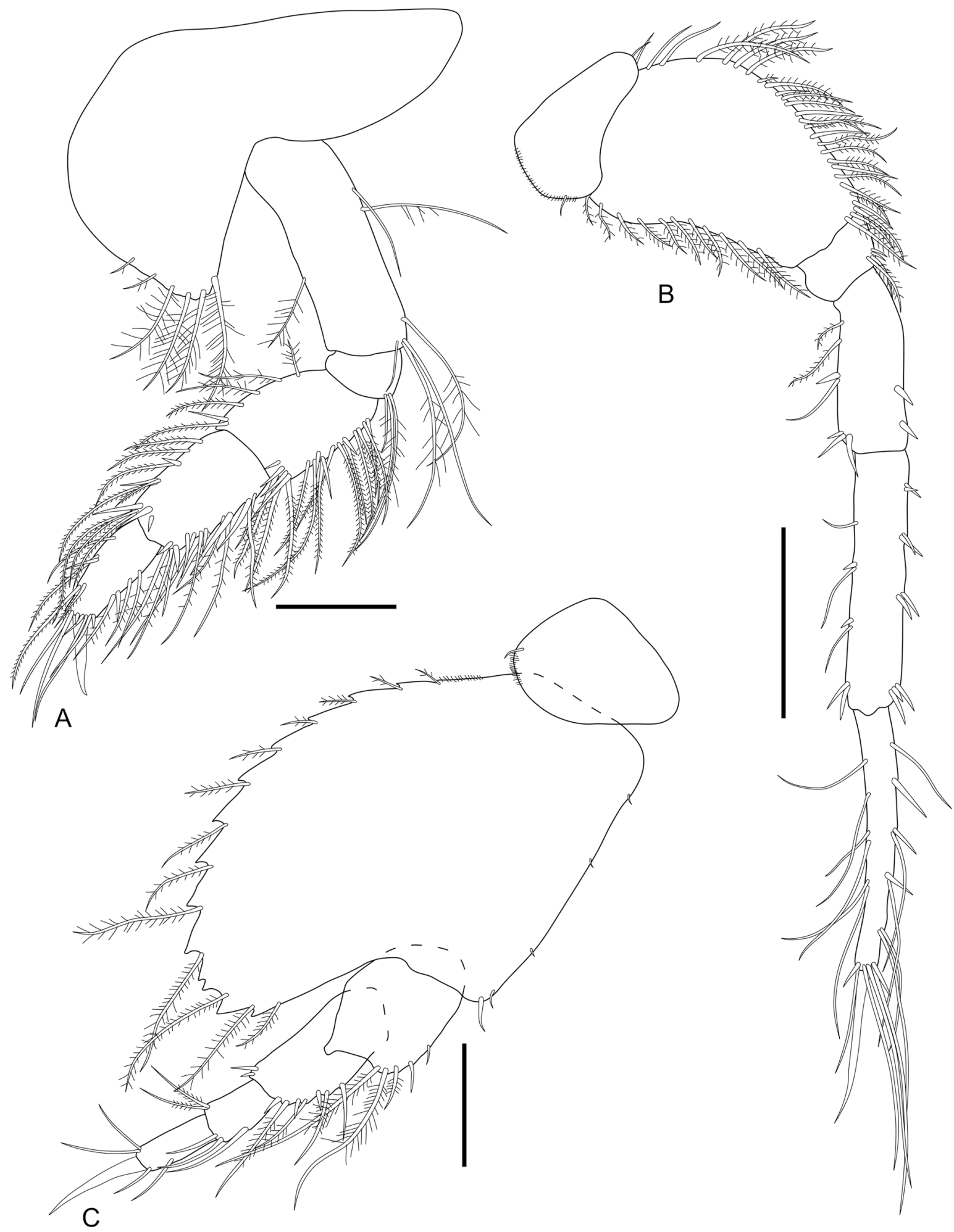

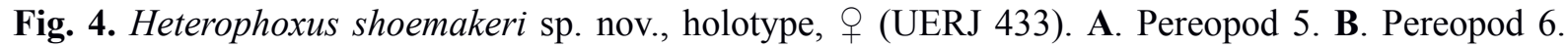
C. Pereopod 7. Scale bars $=0.2 \mathrm{~mm}$. 

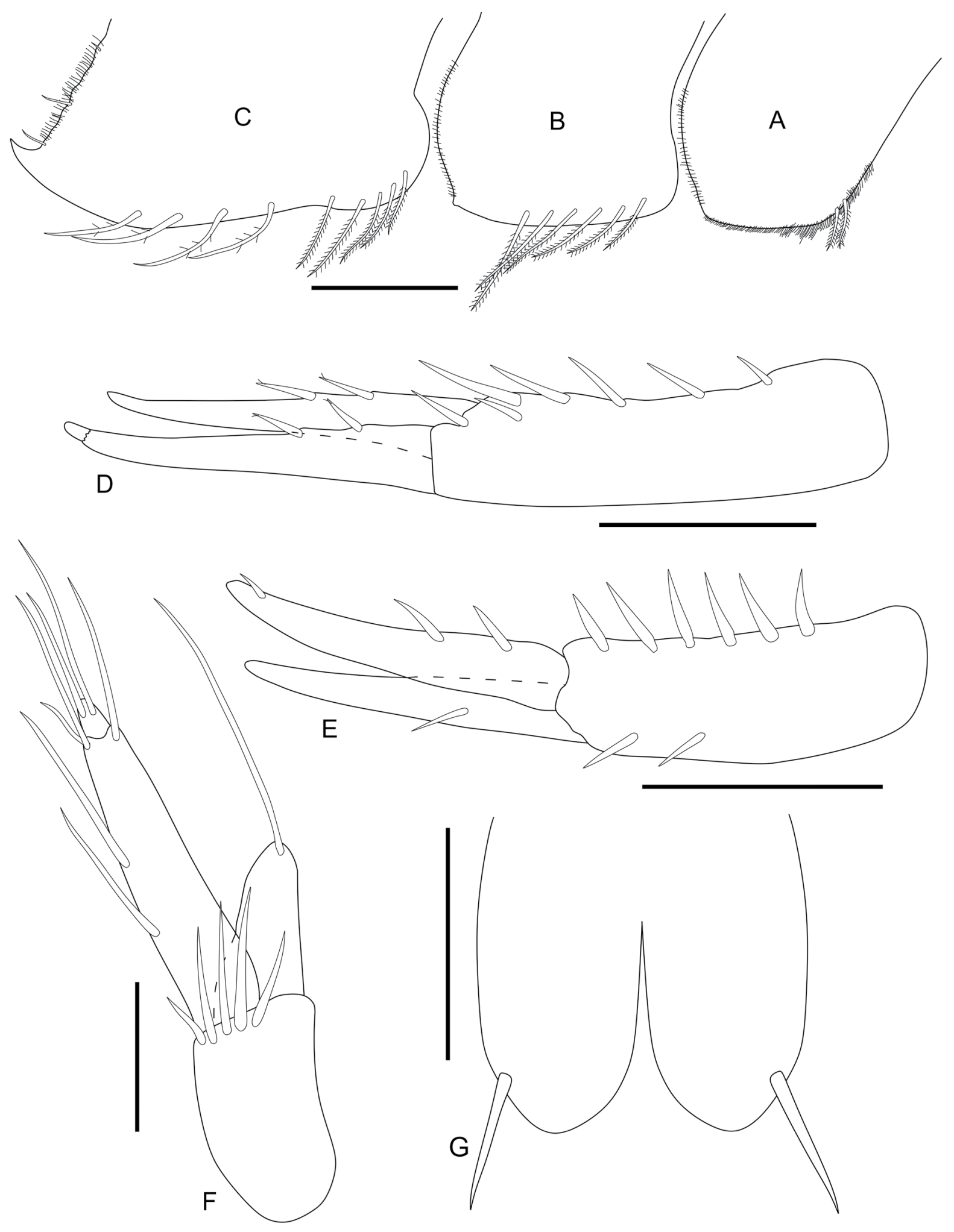

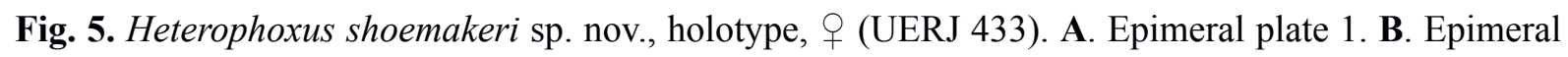
plate 2. C. Epimeral plate 3. D. Uropod 1 E. Uropod 2. F. Uropod 3. G. Telson. Scale bars: A-E, G = $0.2 \mathrm{~mm} ; \mathrm{F}=0.1 \mathrm{~mm}$. 
Paratypes and sexual dimorphism variations

Paratype ( 0 , UERJ 434)

Habitus (Fig. 1B). Smaller in size.

HEAD (Fig. 6A). Eyes larger and more pigmented, kidney-shaped, rostrum unconstricted. Antenna 1 (Fig. 6B), peduncle article 1, stout, about $1.5 \times$ as long as wide, ventral margin with seven brush setae, facial margin with a dense tuft of long setules, dorsal margin with setules medially and one long seta distally; article 2, short, ventral margin with seven long setae; article 3, about $50 \%$ the length of article 2 , ventral margin with two setae, facial margin with two brush setae; primary flagellum 5-articulate; accessory flagellum 7-articulate, with calceoli present on articles 1-3. Antenna 2 (Fig. 6C), peduncle article 1 ensiform; article 3, ventral margin with three setae, dorsal margin covered with long setules; article 4, ventral margin with short to long setae, facial margin with two brush setae and a row of long setae extending to dorsal apex, dorsal margin with long setules; article 5, dorsal margin with four calceoli; flagellum 19-articulate, with setules and 10 calceoli.

Pereon. Gnathopods 1-2 (Fig. 6D-E), similar in size, but more robust and with a longer propodus than in female.

Pleon. Uropod 3 (Fig. 6F), peduncle $1.3 \times$ as long as wide, with seven stout setae distally; outer ramus, article 1, margins covered with long plumose setae, article 2, with two long plumose setae apically; inner ramus, equals outer ramus in length, margins covered with long plumose setae.

Paratype ( $\widehat{c}$ subadult, UERJ 435)

Antenna 2 (Fig. 6G), without calceoli; flagellum stouter and shorter than in adult males, with 12 articles.

\section{Remarks}

The only species of the genus doubtfully cataloged for Brazilian waters is $H$. videns, recorded from São Paulo State. The original description of the species by K.H. Barnard (1930) and subsequent works with diagnoses and illustrations (Schellenberg 1931; Nicholls 1938; J.L. Barnard 1960) are not enough to make a complete comparison between $H$. shoemakeri sp. nov. and $H$. videns. The best-represented scheme of this species in which is possible to check important diagnostic characters was provided by Bellan-Santini (1972). Heterophoxus shoemakeri sp. nov. can be distinguished from $H$. videns by the following states of characters (H. videns characters in parentheses): mandible palp, article 2 curved (straight); maxilliped, outer plate with strongly curved stout setae (not curved); pereopod 6, basis, posterior margin concave (very weakly concave); pereopod 7, basis, posterior margin serrate with acute teeth (large rounded teeth), merus, posterior margin not produced distally (produced into a rounded lobe); epimeral plate 3, posteroventral corner with a long acute projection (short), posterior margin almost straight (sinuous); uropod 3, outer ramus, article 2 clearly present in both sexes (doubtful/absent in males).

\section{Type locality}

Rio de Janeiro State coast $\left(23^{\circ} 25^{\prime} \mathrm{S}, 43^{\circ} 00^{\prime} \mathrm{W}\right)$.

\section{Distribution}

The species is known from the coasts of the states of Rio de Janeiro, Santa Catarina and Rio Grande do Sul (Fig. 7), between 25 and 128 meters depth. 

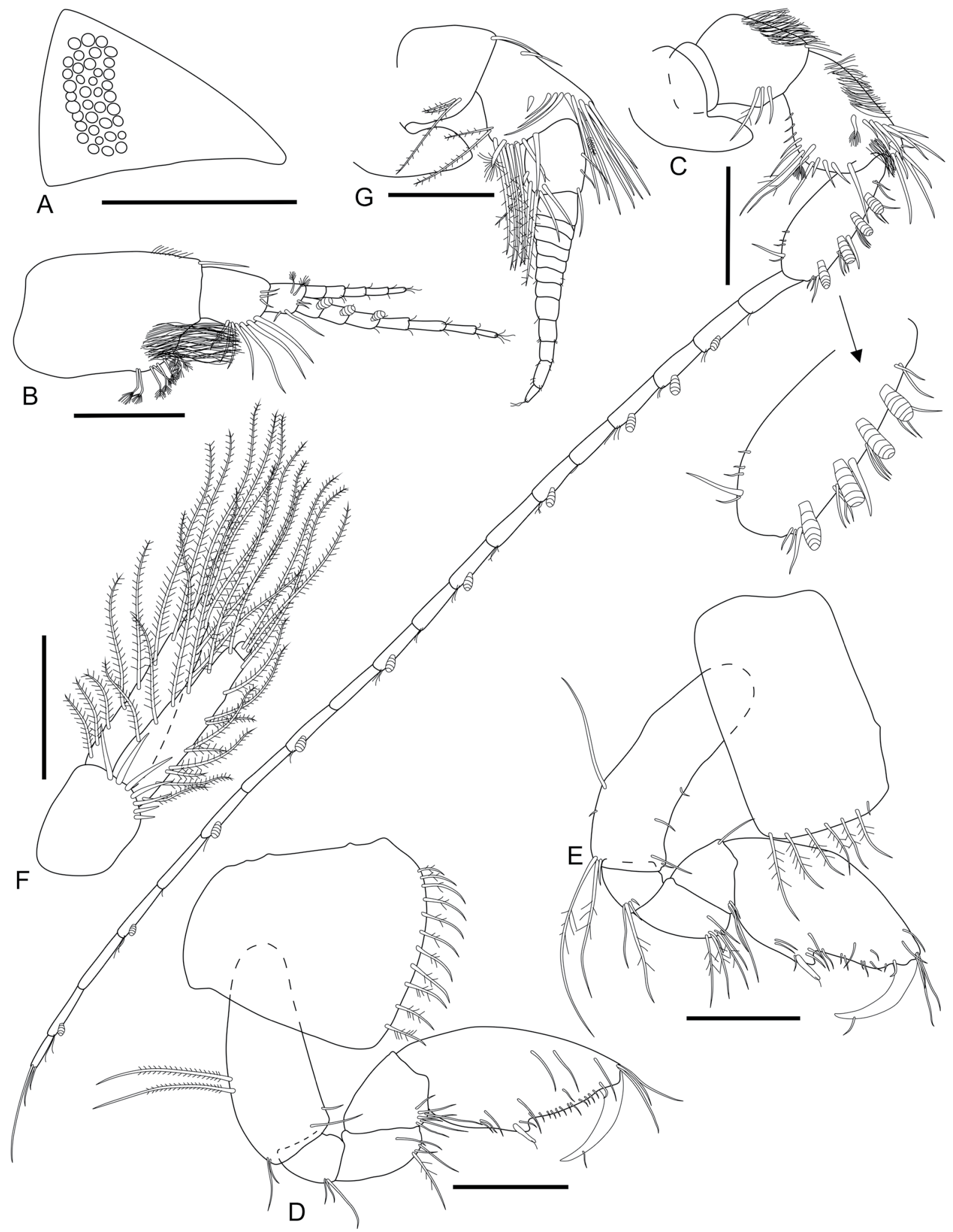

Fig. 6. Heterophoxus shoemakeri sp. nov. A-F. Paratype, $ð$ (UERJ 434). A. Head. B. Antenna 1. C. Antenna 2. D. Gnathopod 1. E. Gnathopod 2. F. Uropod 3. G. Paratype, subadult $\widehat{\partial}$ (UERJ 435). Antenna 2. Scale bars: A $=0.5 \mathrm{~mm} ; \mathrm{B}-\mathrm{F}=0.2 \mathrm{~mm} ; \mathrm{G}=0.1 \mathrm{~mm}$. 


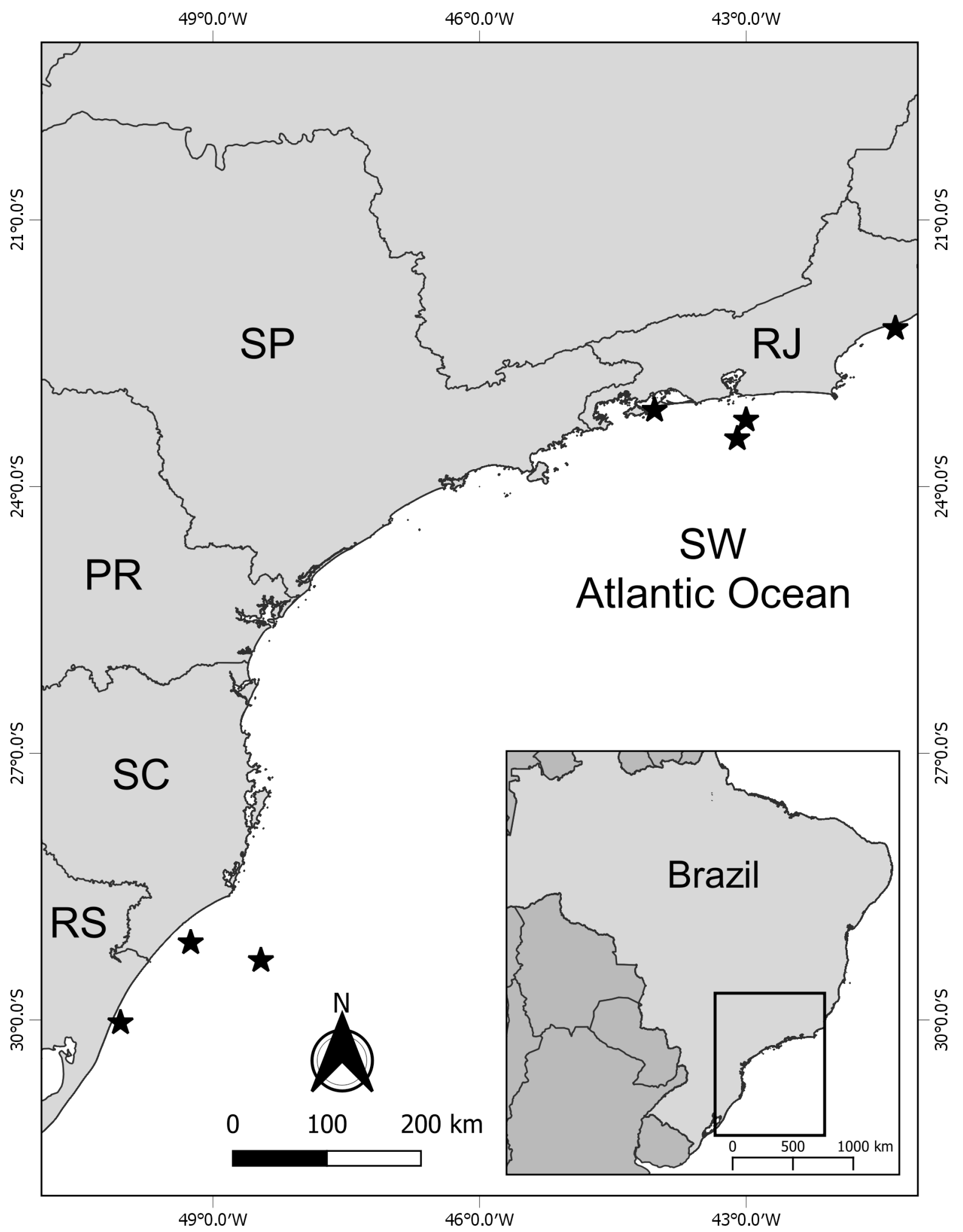

Fig. 7. Distribution of Heterophoxus shoemakeri sp. nov. 


\section{Identification key to species of Heterophoxus of the world}

1. Epimeral plate 3, posteroventral corner with an acute projection .................................................. 3

- Epimeral plate 3, posteroventral corner without projection ....................................................... 2

2. Uropod 1, rami subequal

H. opus Griffiths, 1975

- Uropod 1, outer ramus much shorter than inner H. cephalodens Griffiths, 1975

3. Epimeral plate 3, acute projection medium to long 4

- Epimeral plate 3, acute projection short H. videns K.H. Barnard, 1930

4. Pereopod 7, basis reaching apex of merus 5

- Pereopod 7, basis not reaching apex of merus 7

5. Uropod 1, rami subequal

- Uropod 1, inner ramus about twice the length of outer ....H. pellusidus Ren in Ren \& Huang, 1991

6. Uropod 2, peduncle longer than inner ramus H. ophthalmicus (Schellenberg, 1925)

- Uropod 2, peduncle shorter than inner ramus H. ellisi Jarret \& Bousfield, 1994

7. Antenna 2, article 4 without posteroproximal lobe 8

- Antenna 2, article 4 with posteroproximal lobe H. despard Alonso, 2012

8. Pereopod 4, coxa, posterodorsal margin with moderate to strong excavation 9

- Pereopod 4, coxa, posterodorsal margin with weak excavation H. pennatus Shoemaker, 1925

9. Epimeral plates 1-3, posterior margin without setules 10

- Epimeral plates 1-3, posterior margin covered with setules H. shoemakeri sp. nov.

10. Pereopod 7, merus stout, posterodistal lobe produced H. trichosus K.H. Barnard, 1932

- Pereopod 7, merus slender, posterodistal lobe not produced H. oculatus (Holmes, 1908)

\section{Discussion}

Heterophoxus shoemakeri sp. nov. presents a gap in its distribution along the Brazilian coast, since the species was not found off the states of São Paulo and Paraná during the present study. We believe that further works with a broader sampling effort will be able to report the species for the possibly missing locations.

According to Karaman (1980), there is a clear taxonomic problem within the subfamily Harpiniinae Barnard \& Drummond, 1978, presenting a complex of genera. The genera Heterophoxus and Proharpinia Schellenberg, 1931 differ from the Harpinia complex only by the presence of eyes; nevertheless, it is known that the presence/absence of eyes within amphipods cannot be used as a generic distinctive character (Thurston \& Bett 1993).

Barnard \& Drummond (1978) used male characters for a generic division within Harpiniinae, but male specimens of many species are poorly described or unknown, resulting in an obstacle in defining which genus some species belong to. The authors state that the use of certain taxonomic characters is dubious such as presence/absence of eyes, ensiform first article of antenna 2 and a row of stout setae on uropods 1-2. Hence, the validity of the genera Heterophoxus, Proharpinia, Pseudharpinia Schellenberg, 1931 and Harpiniopsis Stephensen, 1925 is uncertain, and only new and more detailed studies will define whether the four genera should be merged into one group. For now, we consider the four genera as valid and distinct from each other until molecular studies are done to solve these taxonomic issues. 


\section{Acknowledgements}

The authors are grateful to Prof. Dr Maria Teresa Valério-Berardo (Instituto Oceanográfico - Universidade de São Paulo) for providing the studied material. This work is part of the Ph.D. Thesis of LFA in the Post-graduation Program in Animal Biology, Universidade Federal Rural do Rio de Janeiro (PPGBA UFRRJ). This study was financed in part by the Coordenação de Aperfeiçoamento de Pessoal de Nível Superior - Brasil (CAPES) - Finance Code 001.

\section{References}

Alonso G.M. 2012. Amphipod crustaceans (Corophiidea and Gammaridea) associated with holdfasts of Macrocystis pyrifera from the Beagle Channel (Argentina) and additional records from the Southwestern Atlantic. Journal of Natural History 46 (29-30): 1799-1894.

https://doi.org/10.1080/00222933.2012.692825

Alonso de Pina G.M., Rauschert M. \& De Broyer C. 2008. A catalogue of the Antarctic and sub-Antarctic Phoxocephalidae (Crustacea: Amphipoda: Gammaridea) with taxonomic, distribution and ecological data. Zootaxa 1752: 1-40. https://doi.org/10.11646/zootaxa.1752.1.1

Barnard J.L. 1958. Revisionary notes on the Phoxocephalidae (Amphipoda), with a key to the genera. Pacific Science 12: 146-151.

Barnard J.L. 1960. The amphipod family Phoxocephalidae in the Eastern Pacific Ocean, with analyses of other species and notes for a revision of the family. Allan Hancock Pacific Expedition 18: 175-368.

Barnard J.L. \& Drummond M.M. 1978. Gammaridean Amphipoda of Australia, part III: The Phoxocephalidae. Smithsonian Contributions to Zoology 245: 1-551.

https://doi.org/10.5479/si.00810282.103

Barnard J.L. \& Karaman G.S. 1991. The families and genera of marine gammaridean Amphipoda (except marine gammaroids). Part 2. Records of the Australian Museum 13: 419-866.

https://doi.org/10.3853/j.0812-7387.13.1991.367

Barnard K.H. 1930. Crustacea. Part XI. Amphipoda. British Antarctic ("Terra Nova”) Expedition, 1910. Natural History Report, Zoology 8 (4): 307-454. Available from

https://biodiversitylibrary.org/page/49462829 [accessed 20 Dec. 2019].

Bellan-Santini D. 1972. Invertébrés marins des XII ${ }^{\text {ème }}$ et XV $\mathrm{XV}^{\text {ème }}$ Expéditions antarctiques françaises en Terre Adélie. 10. - Amphipodes gammariens. Tethys 4: 157-238.

Garm A. \& Watling L. 2013. The crustacean integument: setae, setules, and other ornamentation. In: Watling L. \& Thiel M. (eds) The Natural History of the Crustacea. Functional Morphology and Diversity: 167-198. Oxford University Press, Oxford.

https://doi.org/10.1093/acprof:osobl/9780195398038.003.0006

Griffiths C.L. 1975. The Amphipoda of Southern Africa Part 5. The Gammaridea and Caprellidea of the Cape Province west of Cape Agulhas. Annals of the South African Museum 67 (5): 91-181.

Jarret N.E. \& Bousfield E.L. 1994. The amphipod superfamily Phoxocephaloidea on the pacific coast of North America. Family Phoxocephalidae. Part II. Subfamilies Pontharpiniinae, Paharpiniinae, Brolginae, Phoxocephalinae, and Harpiniinae. Systematics and distributional ecology. Amphipacifica 3 (4): 71-150.

Karaman G.S. 1980. Cocoharpinia iliffei, new genus and species from Bermuda, with remarks to other genera and species (Fam. Phoxocephalidae). (Contribution to the knowledge of the Amphipoda 103). Studia Marina 9-10 (1): 149-175.

Nicholls G.E. 1938. Amphipoda Gammaridea. Scientific Reports. Australasian Antarctic Expedition 1911-14. Series C. Zoology and Botany 2 (4): 1-145. 
Poore A.G.B. \& Lowry J.K. 1997. New ampithoid amphipods from Port Jackson, New South Wales, Australia (Crustacea: Amphipoda: Ampithoidae). Invertebrate Taxonomy 11: 897-941. https://doi.org/10.1071/IT95045

Ren X. \& Huang L. 1991. Studies on Gammaridea and Caprellidea (Crustacea: Amphipoda) from the northwest waters off the Antarctic Peninsula. Studia Marina Sinica 32: 185-323.

Rodrigues C.W. \& Pires-Vanin A.M.S. 2012. Spatio-temporal and functional structure of the amphipod communities off Santos, Southwestern Atlantic. Brazilian Journal of Oceanography 60 (3): 421-439. https://doi.org/10.1590/S1679-87592012000300013

Schellenberg A. 1931. Gammariden und Caprelliden des Magellangebietes, Südgeorgiens und der Westantarktis. Further Zoological Results of the Swedish Antarctic Expedition 1901-1903 2(6): 1-290.

Serejo C.S. \& Siqueira S.G.L. 2018. Catalogue of the Order Amphipoda from Brazil (Crustacea, Peracarida): Suborders Amphilochidea, Senticaudata and Order Ingolfiellida. Zootaxa 4431 (1): 1-139. https://doi.org/10.11646/zootaxa.4431.1.1

Thurston M.H. \& Bett B.J. 1993. Eyelessness in marine gammaridean Amphipoda (Crustacea): geographical, bathymetric and taxonomic considerations. Journal of Natural History 27: 861-881. https://doi.org/10.1080/00222939300770531

Valério-Berardo M.T. 1992. Composição e distribuição da fauna de Amphipoda de fundos consolidados da região de Ubatuba (São Paulo, Brasil). PhD Thesis, Universidade de São Paulo, Brazil.

Valério-Berardo M.T., Flynn M.N. \& Wakabara Y. 2000. Structure and dynamics of a shelf amphipod taxocoenosis in southeastern Brazil. Bulletin of Marine Science 66 (1): 59-72.

Wakabara Y. \& Serejo C.S. 1998. Malacostraca - Peracarida. Amphipoda. Gammaridea and Caprellidea. In: Young P.S. (ed.) Catalogue of Crustacean of Brazil: 561-594. Museu Nacional Série Livros, Rio de Janeiro.

Wakabara Y., Tararam A.S., Valério-Berardo M.T., Duleba W. \& Leite F.P.P. 1991. Gammaridean and Caprellidean fauna from Brazil. Hydrobiologia 223: 69-77. https://doi.org/10.1007/bf00047629

Manuscript received: 14 September 2019

Manuscript accepted: 15 October 2019

Published on: 14 January 2020

Topic editor: Rudy Jocqué

Desk editor: Pepe Fernández

Printed versions of all papers are also deposited in the libraries of the institutes that are members of the EJT consortium: Muséum national d'histoire naturelle, Paris, France; Meise Botanic Garden, Belgium; Royal Museum for Central Africa, Tervuren, Belgium; Royal Belgian Institute of Natural Sciences, Brussels, Belgium; Natural History Museum of Denmark, Copenhagen, Denmark; Naturalis Biodiversity Center, Leiden, the Netherlands; Museo Nacional de Ciencias Naturales-CSIC, Madrid, Spain; Real Jardín Botánico de Madrid CSIC, Spain; Zoological Research Museum Alexander Koenig, Bonn, Germany; National Museum, Prague, Czech Republic. 